\title{
PROJETO DE LETRAMENTO INFORMACIONAL PARA ESTUDANTES DO ENSINO FUNDAMENTAL: RELATO DE EXPERIÊNCIA
}

\author{
Cintia Kath Blank ${ }^{1}$ \\ cintiadabiblio@gmail.com \\ Renata Braz Gonçalves2 \\ renatabraz@furg.br
}

\begin{abstract}
Resumo: Este texto tem por objetivo apresentar a implementação e avaliação de projeto de Letramento informacional que foi desenvolvido no decorrer do ano de 2015 pela bibliotecária de uma escola de ensino fundamental da rede pública de ensino da cidade do Rio Grande/RS. Inicialmente apresenta breve referencial teórico acerca do tema letramento informacional, posteriormente descreve o projeto, seus objetivos, etapas realizadas e, por fim analisa os resultados atingidos com a implementação do projeto. Subsidiado teoricamente e metodologicamente pela produção de Gasque (2012) sistematizada na obra "Letramento informacional", e utilizando recursos providos pelo Ministério da Educação para as bibliotecas escolares, o referido projeto objetivou promover o desenvolvimento de competências e habilidades informacionais em estudantes do $4^{\circ}$ ano do ensino fundamental da referida escola. Dessa forma, este relato de experiência busca divulgar as experiências e avaliações do referido projeto, como a importância e viabilidade do mesmo, a motivação dos estudantes para o desenvolvimento das atividades, a falta de uma cultura de informação e pesquisa na comunidade escolar, assim como a necessidade de adaptação dos materiais aos objetivos do letramento informacional. Como considerações finais pontua-se a importância do desenvolvimento e da comunicação por parte dos bibliotecários de atividades práticas envolvendo o letramento informacional, assim como a produção de orientações didáticas e teóricas específicas para a aplicação do letramento informacional no contexto educacional, social e cultural brasileiro.
\end{abstract}

Palavras-chave: Letramento informacional. Biblioteca escolar. Comportamento informacional.

\section{INTRODUÇÃO}

Uma pessoa letrada informacionalmente é aquela capaz de perceber que necessita de informação, procurá-la, identificá-la, analisar o que encontra e divulgar de maneira ética e eficiente.

A ampliação da circulação de informações em nosso cotidiano possibilitada pelas Tecnologias de Informação e Comunicação (TIC's), implica que os indivíduos estejam letrados informacionalmente e proporciona ao bibliotecário novas dimensões ao seu trabalho.

Diante da explosão informacional e das inovações tecnológicas ocorridas a partir de meados do século XX, surgiu em novembro de 1974 nos Estados Unidos, a expressão Information Literacy mencionada, primeiramente, pelo bibliotecário Paul Zurkowsky no relatório The information service environment relationships and priorities (ZURKOWSKI, 1974) destacando a necessidade do trabalho com informação frente ao momento de transição social e tecnológica da época. Já no Brasil, a produção bibliográfica sobre Information Literacy iniciou em 2000, com Caregnato (2000) e tem sido trabalhada quase que exclusivamente pela Biblioteconomia e pela Ciência da Informação (GASQUE, 2012).

A partir deste momento, é possível encontrar trabalhos desenvolvidos no Brasil que adotam variadas traduções para o termo original Information Literacy, são elas: letramento informacional, competência informacional, alfabetização informacional, entre outros, ainda que suas definições sejam,

\footnotetext{
1 Mestre em Educação (PPGEdu/FURG); Bibliotecária escolar da Prefeitura Municipal do Rio Grande; E-mail: cintiadabiblio@gmail.com

${ }^{2}$ Doutora em Educação (PPGE/UFPEL); Professora do Curso de Biblioteconomia da Universidade Federal do Rio Grande FURG; Endereço: Instituto de Ciências Humanas e da Informação. Campus Carreiros: Av. Itália km 8 Bairro Carreiros - CEP: 96203-900; Telefone: (53) 3233 6687; Correio eletrônico: renatabraz@ furg.br
} 
em geral, muito singulares. Campello (2009) compreende que o Letramento informacional implicaria fundamentalmente que as pessoas tivessem capacidade de entender suas necessidades de informação e de localizar, selecionar e interpretar informações, utilizando-as de forma crítica e responsável.

Gasque (2010, p.86) considera "a alfabetização informacional como primeira etapa" a qual envolveria o "conhecimento básico dos suportes de informação". De acordo com a autora, nessa etapa estariam contemplados a aprendizagem de noções básicas como o uso de dicionários, enciclopédias e recursos computacionais, devendo ser trabalhada desde a educação infantil a fim de promover uma visão positiva frente ao processo de busca e uso de informações.

$\mathrm{Na}$ continuidade deste processo, segundo a autora, o conceito de letramento informacional estaria relacionado à "capacidade de buscar e usar a informação eficazmente" (GASQUE, 2010, p. 86). Nesta etapa estariam contempladas as tarefas de produção de textos próprios, aplicação da informação em atividades cotidianas entre outras, exigindo um maior engajamento do sujeito no universo informacional.

Já o termo "competência informacional", de acordo com essa autora, parece estar mais ligado ao mundo do trabalho ou a aprofundamentos mais próprios do ensino médio, técnico ou superior segundo estudos e pesquisas da área.

Belluzzo (2014) destaca que o acesso à informação já não é mais o ponto central do desenvolvimento da sociedade contemporânea, mas, mas o que se fazer com o uso da informação. Assim, a autora afirma que a Competência em Informação (CoInFo) é caracterizada por uma multiplicidade de interesses, abordagens de pesquisa e princípios teóricos e que a mesma deve ser observada como um aspecto relevante no contexto social, que advém de duas dimensões:

[...] a primeira, um domínio de saberes e de habilidades de diversas naturezas que permite a intervenção prática na realidade, e a segunda, uma visão crítica do alcance das ações e o compromisso com as necessidades mais concretas que emergem e caracterizam o atual contexto social (BELLUZZO, 2007, p. 34).

Em 2014, realizou-se o "III Seminário de Competência em Informação: cenários e tendências", com o tema central "Competência em Informação e Redes de Conhecimento Colaborativo", na Cidade de Marília, Estado de São Paulo, Brasil. Nesse evento, foi redigida a Carta de Marília, a qual apresenta constatações e diretrizes que levam em consideração a emergência e a importância da CoInfo para o Brasil nos últimos anos, e a necessidade de compartilhamento de experiências e vivências aplicáveis à realidade brasileira (UNESP, 2014). A partir de então, verificamos que a denominação Competência em Informação bem como sua sigla - CoInFo - passam a ser adotados com mais intensidade pelos pesquisadores, que trabalham com essa temática..

Ainda assim, o desenvolvimento deste relato foi embasado pela definição de letramento informacional proposta por Gasque (2012, p.28), que define letramento informacional como sendo um "processo de desenvolvimento de competências para localizar, selecionar, acessar, organizar, usar informação e gerar conhecimento, visando à tomada de decisão e à resolução de problemas".

Segundo a mesma autora, o letramento informacional teria como objetivo adaptar e socializar os indivíduos na sociedade da aprendizagem. E, segundo ela, isso ocorreria quando o indivíduo desenvolve as capacidades de:

- determinar a extensão das informações necessárias;

- acessar a informação de forma efetiva e eficientemente;

- avaliar criticamente a informação e suas fontes;

- incorporar a nova informação ao conhecimento prévio;

- usar a informação de forma efetiva para atingir objetivos específicos;

- compreender os aspectos econômico, legal e social do uso da informação, bem como acessá-la e usá-la ética e legalmente (GASQUE, 2012, p. 32):

O termo letramento pode ser considerado relativamente novo, originando-se na década de 1980 (GASQUE, 2010), e recebendo especial atenção pela área de educação, embora esta terminologia já seja empregada em várias áreas do conhecimento onde cada qual determina uma ênfase ou complemento ao 
utilizá-la, chegando ao ponto de atualmente ser considerada a existência de uma multiplicidade de letramentos. No campo da educação formal, no que concerne a área de alfabetização e letramento, este último é compreendido como o domínio efetivo da escrita em situações cotidianas a fim de atingir diferentes objetivos de maneira competente (SOARES, 1998).

Trazendo essa discussão para a área de informação, ratifica-se o posicionamento de Campello (2009) ao afirmar que o letramento informacional deve ser abordado juntamente com outras ações de letramento em geral. Para a autora, deve ser evitada a fragmentação da aprendizagem, e dessa forma, o bibliotecário deve desenvolver sua ação educativa em conjunto com os professores.

De acordo com a mesma autora, as bases teóricas para o desenvolvimento do letramento informacional nas áreas de Biblioteconomia e Ciência da Informação estão fundamentadas principalmente a partir da institucionalização do serviço de referência e dos estudos de usuários (CAMPELLO, 2009).

Possuindo uma abordagem essencialmente construtivista, muitos estudos e pesquisas acerca do letramento informacional centram-se em autores como Jean Piaget, John Dewey e Jerome Bruner. Neste sentido, observa-se a integração entre os conhecimentos e práticas da Biblioteconomia com a Educação, objetivando aprofundar questões de aprendizagem, informação, conhecimento, comportamento informacional e pesquisa no espaço escolar, de maneira colaborativa, integrada e planejada.

Atualmente tem-se buscado investir em projetos e programas de letramento informacional no Brasil, contudo, nota-se que as iniciativas ainda são incipientes, o que corroboramos com Dudziak (2008) quando aponta que, apesar dos avanços nos últimos anos sobre information literacy (letramento informacional), ainda existem pontos a serem trabalhados para ampliar sua disseminação, dos quais destaca:

- falta de compreensão do conceito;

- fragmentação de iniciativas e interesses;

- terminologia e abrangência não uniformes;

- institucionalização do tema ainda é precária;

- carência de estudos teóricos, metodológicos e práticos mais aprofundados e abrangentes;

- sub-utilização do conceito;

- subestimação de sua importância por parte dos bibliotecários, profissionais da informação, educadores e administradores, e

- carência de ações sistêmicas (DUDZIAK, 2008, p. 43).

Vemos que são muitos os aspectos que necessitam ser aprofundados e que trabalhos que divulguem ações que visem promover o letramento informacional ainda são escassos. Este fato nos mobilizou a divulgar este relato de experiência como forma de contribuir com o desenvolvimento da temática do letramento informacional de maneira prática e metodológica.

Assim sendo, este artigo objetiva apresentar a implementação e avaliação de projeto de Letramento informacional que foi desenvolvido no decorrer do ano de 2015 pela bibliotecária Cintia Blank em uma escola de ensino fundamental da rede pública municipal da cidade do Rio Grande/RS. O desenvolvimento do projeto foi fundamentado na proposta metodológica apresentada pela professora $\mathrm{Dr}^{\mathrm{a}}$ Kelley Cristine Gasque no livro Letramento informacional (2012). A seguir, apresentamos os passos e atividades que integraram a execução do projeto.

\section{DESENVOLVIMENTO DO PROJETO}

O projeto de letramento informacional foi desenvolvido pela bibliotecária da escola, Cintia Blank, durante o período compreendido entre os meses de março e novembro de 2015. O projeto abrangeu duas turmas de uma escola pública da rede municipal de educação localizada na periferia da cidade do Rio Grande/RS, totalizando 40 estudantes envolvidos com idades entre 9 e 11 anos. Os encontros ocorreram semanalmente, tinham a duração de 45 minutos em cada turma, e eram desenvolvidos no espaço da sala de aula.

O aporte teórico e os conteúdos trabalhados no projeto basearam-se nas indicações de Gasque (2012), sistematizadas na obra "Letramento informacional", especificamente nas partes tocantes a 


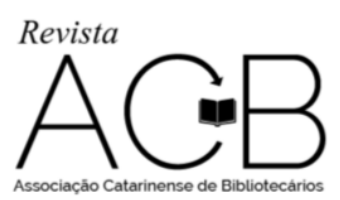

Projeto de Letramento Informacional para estudantes do ensino fundamental: relato de experiência - Cintia Kath Blank e Renata Braz Gonçalves

educação básica e ensino fundamental. Esta obra de Gasque (2012, p.19) "estrutura-se em cinco capítulos, que abordam desde o conceito de letramento informacional até estratégias de ensino-aprendizagem e questões práticas", sendo uma publicação de livre acesso, seu conteúdo completo pode ser encontrado na web em formato PDF. Assim, elaborando uma proposta de conteúdos pertinentes a cada ano escolar relacionados com os objetivos do letramento informacional e com as fases de desenvolvimento das crianças e jovens, esta proposta sistematiza o ano escolar, a idade dos estudantes, conteúdos a serem trabalhados e as habilidades a serem desenvolvidas ao longo das séries/anos.

Partindo desta proposta, desenvolveram-se atividades a serem trabalhadas com os educandos enfocando os conteúdos e habilidades indicados para o $4^{\circ}$ ano do ensino fundamental conforme aponta a Figura 1, mas também foram abordadas habilidades pertencentes a anos escolares anteriores, conforme se mostrava necessário durante o andamento do projeto e explicitado nos quadros que seguem. Assim, optou-se por utilizar materiais disponibilizados a todas as escolas públicas brasileiras pelo Programa Nacional Biblioteca na Escola (PNBE) do Ministério da Educação (MEC), a fim de que a experiência, ora relatada, fosse passível de ser adotada de maneira parcial ou total por outras escolas públicas. Através do PNBE são distribuídos a todas as escolas públicas cadastradas no censo escolar, acervos compostos por obras de literatura, de referência, de pesquisa e de outros materiais relativos ao currículo nas áreas de conhecimento da educação básica, com vista à democratização do acesso às fontes de informação, ao fomento à leitura e à formação de alunos e professores leitores e ao apoio à atualização e ao desenvolvimento profissional do professor. (FUNDO NACIONAL..., 2012). O PNBE é composto pelos seguintes gêneros literários: obras clássicas da literatura universal; poema; conto, crônica, novela, teatro, texto da tradição popular; romance; memória, diário, biografia, relatos de experiências; livros de imagens e histórias em quadrinhos. Na figura 1, apresentamos os conteúdos e habilidades propostos por Gasque (2012) para serem desenvolvidos com os alunos do quarto ano do ensino fundamental.

Figura 1 - Proposta de conteúdos de Letramento Informacional para o $4^{\circ}$ ano do Ensino Fundamental.
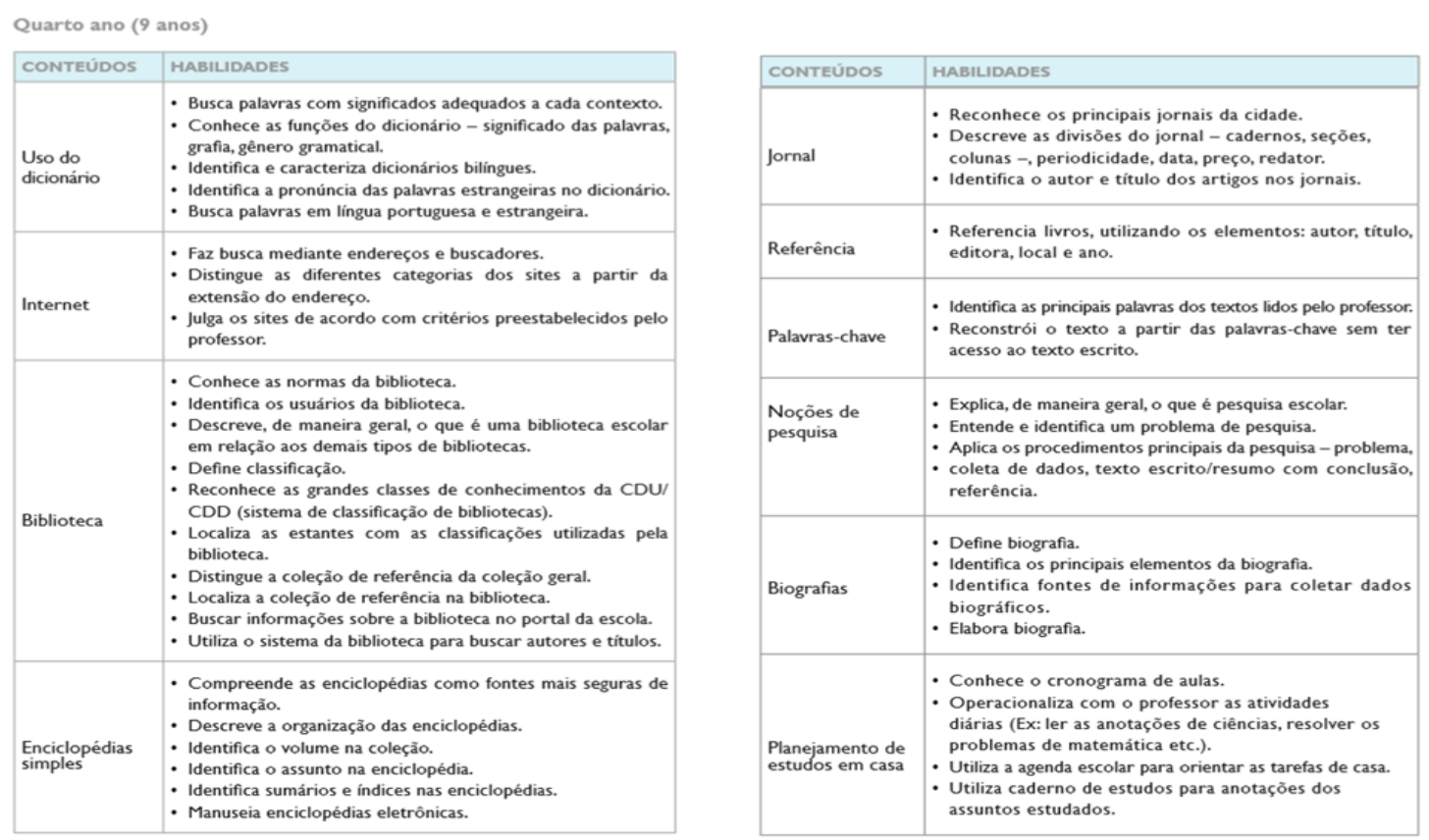

Fonte: Gasque (2012, p.96-97)

Fundamentado nessa proposição, o projeto foi estruturado a partir da utilização de quatro textos de periódicos pertencentes ao Programa Nacional Biblioteca na Escola (PNBE). Assim, foram desenvolvidas atividades lúdicas e educativas que facilitassem atingir os objetivos de cada temática. Ainda que os referidos textos tenham servido de base para o desenvolvimento das competências e habilidades as quais se objetivavam abordar, vale ressaltar que as atividades foram desenvolvidas a partir da proposta de conteúdos indicadas por Gasque (2012). 
A metodologia de avaliação da implementação do projeto ocorreu por meio da observação sistemática no momento do desenvolvimento das atividades. Foram observadas facilidades e dificuldades encontradas pelos estudantes para o desenvolvimento das atividades propostas, bem como seus conhecimentos prévios e a motivação para realização das mesmas.

A seguir, serão detalhadas as quatro temáticas que fundamentaram a aplicação do projeto de letramento informacional. Ressalva-se, que os itens apresentados foram desenvolvidos no decorrer de vários encontros e que as turmas demandaram um tempo próprio para realizar cada etapa. Assim, o desenvolvimento do projeto foi realizado de acordo com as necessidades e com o ritmo dos estudantes. Passamos, então, ao primeiro conjunto de atividades.

\subsection{PRIMEIRO CONJUNTO DE ATIVIDADES: A MAIOR BIBLIOTECA DO MUNDO}

O texto "A maior biblioteca do mundo" (FUNARI, 2012) é um artigo extraído da Revista Ciência Hoje das Crianças, que aborda a Biblioteca de Alexandria e o contexto histórico em que ela surgiu. $\mathrm{O}$ texto discorre sobre as diferentes fases de apogeu e de destruição pelas quais a biblioteca passou, enfatizando a importância histórica e cultural da mesma.

Ações realizadas:

- A atividade iniciou com a entrega de uma cópia do texto a cada estudante. O primeiro momento destinava-se a uma leitura silenciosa individual. Posteriormente, ocorreu a leitura em voz alta, mediante a colaboração voluntária dos discentes que desejassem participar.

- Neste momento, foram dialogadas as diferenças entre o referido texto (informativo) com os livros que eram emprestados na biblioteca (literários) e os livros utilizados com os professores (didáticos).

- Em duplas, questões para interpretação foram entregues para serem respondidas em seus cadernos e posteriormente corrigidas oralmente com o grande grupo. Neste encontro foi levado para a sala de aula um mapa mundi e um globo terrestre a fim de que os alunos pudessem localizar o Egito (local ao qual o texto se refere) e juntos observassem as características, semelhanças e diferenças entre um mapa e um globo.

- Uma lista de palavras chamada "outros tipos de "tecas" " foi entregue contendo o nome de diferentes coleções, cujos vocábulos contém o sufixo 'teca' (discoteca, hemeroteca,...) para seus significados serem procurados em dicionários vernáculos disponíveis na biblioteca, conforme demonstra a Figura 2.

- As palavras que não constavam nos dicionários impressos da biblioteca foram pesquisadas no dicionário on-line Priberam (DICIONÁRIO, 2016). Com todas as respostas do significado das palavras, dialogou-se sobre as características dos dicionários impressos e on-line.

A escolha por este texto para o início do projeto se deu em virtude da história da Biblioteca de Alexandria ser abordada com uma linguagem própria para crianças, ao mesmo tempo em que traz informações importantes sobre o conceito de biblioteca, bibliotecário, livro e suportes de informação. Foi possível, partindo destas informações, relacionar diferentes tipos de bibliotecas, a profissão do bibliotecário, as formas de produção dos livros, assim como diferentes tipos de leitura, suportes de informação e tecnologias da informação e comunicação, introduzindo a importância do trabalho com informação, pesquisa e construção do conhecimento desde os primeiros anos escolares (GASQUE, 2012). 


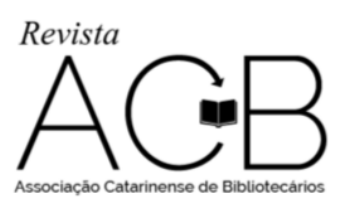

Figura 2 - Utilização de dicionários pertencentes ao acervo da biblioteca da escola

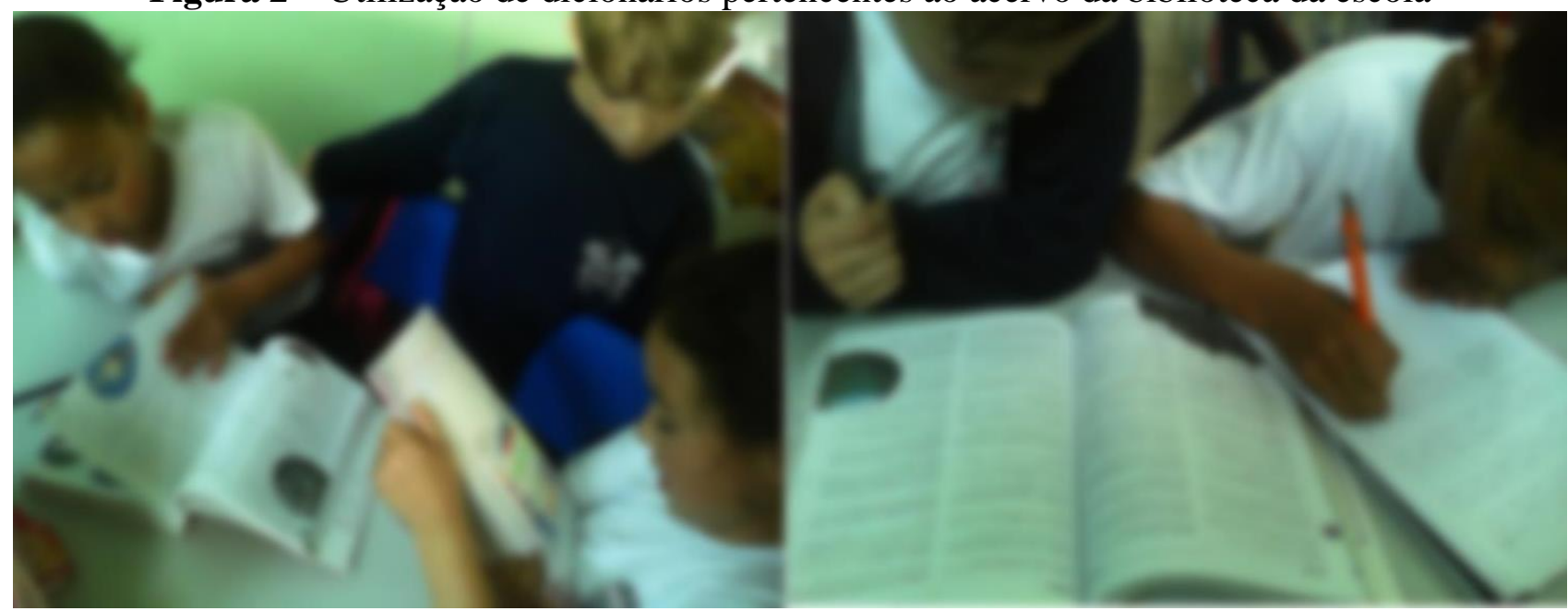

Fonte: Elaboração das autoras (A utilização do efeito desfoque na foto objetivou a não identificação dos participantes)

A seguir apresentamos o Quadro 1 que demonstra a relação dos conteúdos e habilidades propostos por Gasque (2012) com a primeira atividade desenvolvida a partir do texto "A maior biblioteca do mundo". Vale ressaltar que, em todos os quadros que seguem, além dos conteúdos, competências e habilidades propostos por Gasque (2012), são indicadas as atividades realizadas, bem como é descrita a avaliação do desenvolvimento de cada atividade.

Quadro 1 - A maior biblioteca do mundo

\begin{tabular}{|c|c|c|c|}
\hline Conteúdos & Competências e Habilidades & Atividades & Avaliação do desenvolvimento \\
\hline \multirow[t]{2}{*}{ Uso do dicionário } & $\begin{array}{l}\text { Busca palavras com significados } \\
\text { adequados a cada contexto. }\end{array}$ & \multirow[t]{2}{*}{$\begin{array}{l}\text { Lista de palavras "outros } \\
\text { tipos de "tecas". }\end{array}$} & \multirow{2}{*}{$\begin{array}{l}\text { A atividade foi bem recebida. } \\
\text { Algumas dúvidas foram } \\
\text { surgindo e alguns estudantes } \\
\text { não sabiam utilizar o dicionário, } \\
\text { mas ao final da atividade já } \\
\text { pareciam mais seguros. }\end{array}$} \\
\hline & $\begin{array}{l}\text { Conhece as funções do dicionário - } \\
\text { significado das palavras, grafia, } \\
\text { gênero gramatical. }\end{array}$ & & \\
\hline \multirow[t]{2}{*}{ Internet } & $\begin{array}{l}\text { Faz busca mediante endereços e } \\
\text { buscadores. }\end{array}$ & \multirow[t]{2}{*}{$\begin{array}{l}\text { Uso do dicionário online } \\
\text { Priberam. }\end{array}$} & \multirow{2}{*}{$\begin{array}{l}\text { Foram muito receptivos e } \\
\text { demostraram conhecimento em } \\
\text { buscas deste tipo. }\end{array}$} \\
\hline & $\begin{array}{l}\text { Compreende que existem } \\
\text { informações incorretas na internet. }\end{array}$ & & \\
\hline \multirow[t]{3}{*}{ Biblioteca } & $\begin{array}{l}\text { Descreve, de maneira geral, o que é } \\
\text { uma biblioteca escolar em relação } \\
\text { aos demais tipos de bibliotecas. }\end{array}$ & Interpretação do texto. & $\begin{array}{l}\text { A partir da leitura do texto, o } \\
\text { debate sobre diferentes tipos de } \\
\text { bibliotecas foi acontecendo. A } \\
\text { maioria demonstrou só } \\
\text { conhecer a biblioteca da escola. }\end{array}$ \\
\hline & $\begin{array}{l}\text { Distingue a coleção de referência } \\
\text { da coleção geral. }\end{array}$ & \multirow[t]{2}{*}{$\begin{array}{l}\text { Uso de dicionários } \\
\text { impressos do PNBE. }\end{array}$} & \multirow{2}{*}{$\begin{array}{l}\text { Embora todos já conhecessem } \\
\text { dicionários, alguns não tinham } \\
\text { bem clara a ideia de que eram } \\
\text { armazenados na biblioteca da } \\
\text { escola e em que parte se } \\
\text { localizavam. }\end{array}$} \\
\hline & $\begin{array}{l}\text { Localiza a coleção de referência na } \\
\text { biblioteca. }\end{array}$ & & \\
\hline \multirow[t]{2}{*}{$\begin{array}{l}\text { Planejamento de } \\
\text { estudos em casa }\end{array}$} & Conhece o cronograma de aulas. & $\begin{array}{l}\text { Projeto do letramento } \\
\text { informacional dentro do } \\
\text { quadro de horários }\end{array}$ & $\begin{array}{l}\text { Rapidamente, os discentes } \\
\text { assimilam os dias, horários e } \\
\text { objetivos do projeto. }\end{array}$ \\
\hline & $\begin{array}{l}\text { Utiliza caderno de estudos para } \\
\text { anotações dos assuntos estudados. }\end{array}$ & $\begin{array}{l}\text { Anotações no decorrer da } \\
\text { atividade. }\end{array}$ & $\begin{array}{lcr}\text { Dificuldade } & \text { para } & \text { fazer } \\
\text { anotações } & \text { sobre os } & \text { assuntos } \\
\text { estudados, bem como retomar } \\
\text { anotações } & \text { de } & \text { encontros } \\
\text { anteriores. } & & \\
\end{array}$ \\
\hline Ficção e não-ficção & $\begin{array}{l}\text { Descreve as diferenças entre os } \\
\text { livros de ficção e não ficção. }\end{array}$ & Análise do texto. & $\begin{array}{l}\text { Apresentaram facilidade para } \\
\text { diferenciação entre textos } \\
\text { informativos e de ficção. }\end{array}$ \\
\hline
\end{tabular}

Fonte: Elaboração das autoras. 
Ao analisarmos o Quadro 1, constatamos que não houve resistência por parte dos estudantes para realização das atividades. No que se refere ao conhecimento e uso de dicionários, alguns estudantes não sabiam como utilizá-los ou que os mesmos estariam armazenados e disponíveis na biblioteca da escola. Uma parte dos estudantes também não sabia diferenciar obras de referência de outros tipos de obras. Acreditamos que essas competências e habilidades já deveriam ter sido desenvolvidas anteriormente em alunos que se encontram nessa fase escolar.

Verificamos, ainda, que as experiências dos estudantes, no que se refere às bibliotecas, se resume à biblioteca da escola, evidenciando a importância da mesma na formação dessas crianças. Possivelmente, pela falta de prática, a atividade em que os alunos demonstraram mais dificuldade em realizar foi a que estava relacionada ao planejamento de estudos em casa e compreendia utilizar o caderno de estudos para anotações dos assuntos estudados. Essa dificuldade prejudicou a retomada de atividades em encontros posteriores. Apesar de alguns contratempos, cremos que a realização desse primeiro conjunto de ações, foi satisfatório, uma vez que os estudantes além de estarem totalmente motivados, avançaram no desenvolvimento das habilidades e competências trabalhadas pela bibliotecária.

A seguir, passamos ao segundo grupo de ações realizadas.

\subsection{SEGUNDO CONJUNTO DE ATIVIDADES: JOGO DA VIDA DO LIVRO}

Neste conjunto de atividades, a bibliotecária utilizou como mote o Jogo de tabuleiro denominado "Jogo da Vida", extraído da Revista Nova Escola (JOGO..., 2013). O referido jogo constitui-se de uma atividade lúdica a qual tem por objetivo conscientizar os "jogadores" sobre os cuidados que devem ter em relação a todos os tipos de livros. O jogo destaca os cuidados com os livros didáticos, por serem em sua maioria reutilizáveis por vários anos e também por fazerem parte do cotidiano das crianças.

Ações realizadas:

- Após conversa com a turma sobre as normas da biblioteca, formas de funcionamento, tipos de materiais e outros aspectos referentes à biblioteca da escola, passou-se à distribuição do jogo.

- Separados em duplas, foi entregue uma cópia de cada tabuleiro e as regras do jogo foram explicadas. A Figura 3 reproduz a imagem do tabuleiro utilizado nesta atividade.

Figura 3 - Tabuleiro "Jogo da vida do livro"

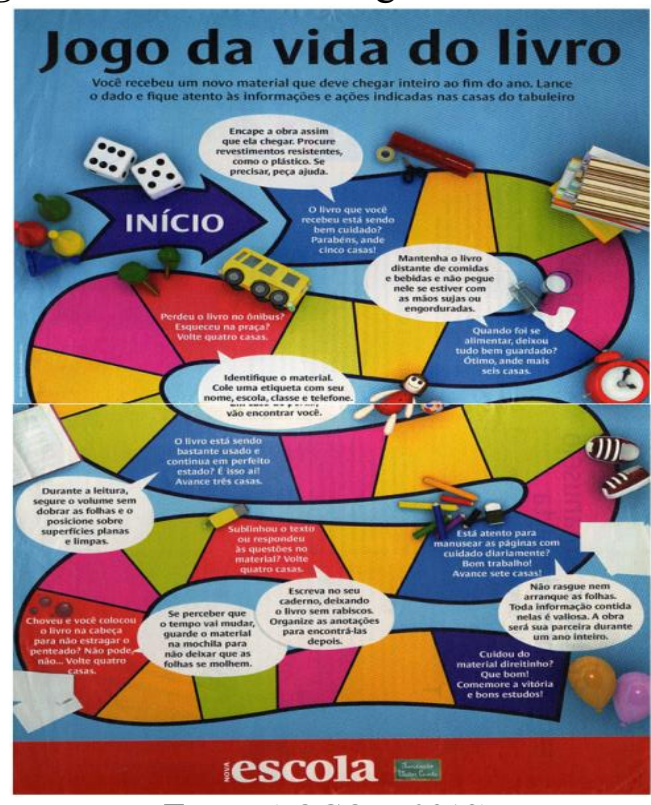

Fonte: (JOGO..., 2013). 
A opção por utilizar este material residiu na importância da ludicidade como fator essencial na educação. O lúdico, segundo Piaget (1964), faz parte de nossa vida desde o nascimento por meio de diferentes tipos de jogos. Assim, dentre os diferentes tipos de jogos, como o de exercício (repetição) e o simbólico (faz de conta), utilizou-se nesta atividade o jogo de regras, que de acordo com Piaget (1964), são aqueles jogos regulamentados, seja por um código transmitido de gerações em gerações ou por acordos momentâneos, em que estimula a socialização, o intelecto e as operações sensório-motoras. Assim, esta atividade permitiu relacionar a situação de que assim como o jogo necessita de regras para acontecer, a biblioteca também possui suas regras para funcionar.

Quadro 2 - Jogo da vida do livro

\begin{tabular}{|c|c|c|c|}
\hline Conteúdos & Competências e Habilidades & Atividades & Avaliação do desenvolvimento \\
\hline \multirow[t]{8}{*}{ Biblioteca } & Conhece as normas da biblioteca. & \multirow[t]{8}{*}{ Jogo de tabuleiro. } & \multirow{8}{*}{$\begin{array}{l}\text { Demonstravam conhecimento } \\
\text { do conteúdo, embora alguns } \\
\text { confessassem já ter agido de } \\
\text { forma diferente. } \\
\text { A atividade provocou certo } \\
\text { tumulto entre os estudantes, e } \\
\text { como as questões do jogo já } \\
\text { eram de conhecimento dos } \\
\text { discentes, não se configurou em } \\
\text { desafio, logo fazendo com que } \\
\text { perdessem o interesse na } \\
\text { atividade. }\end{array}$} \\
\hline & Identifica os usuários da biblioteca. & & \\
\hline & $\begin{array}{l}\text { Descreve, de maneira geral, o que é } \\
\text { uma biblioteca escolar em relação } \\
\text { aos demais tipos de bibliotecas. }\end{array}$ & & \\
\hline & $\begin{array}{l}\text { Localiza as estantes com as } \\
\text { classificações } \\
\text { biblioteca. }\end{array}$ & & \\
\hline & $\begin{array}{l}\text { Distingue a coleção de referência } \\
\text { da coleção geral. }\end{array}$ & & \\
\hline & $\begin{array}{l}\text { Localiza a coleção de referência na } \\
\text { biblioteca. }\end{array}$ & & \\
\hline & $\begin{array}{l}\text { Desenvolve } \\
\text { materiais } \\
\text { biblioteca. }\end{array}$ & & \\
\hline & $\begin{array}{l}\text { Sabe portar-se adequadamente na } \\
\text { biblioteca. }\end{array}$ & & \\
\hline
\end{tabular}

Fonte: Elaboração das autoras

Ao analisar a realização da atividade, notamos boa receptividade dos estudantes com as tarefas propostas, embora demostrassem certa dificuldade com as regras e a dinâmica do jogo. Observamos que os educandos não possuíam o hábito de brincar com jogos de tabuleiros e, por vezes, pareciam não considerar esta atividade como um momento de aprendizado, e sim de distração. Creditamos este fato a uma cultura educativa e informacional tantas vezes presente nas escolas, que se manifesta na cópia, na memorização e na seleção de conteúdos e métodos de ensino a serem tachados como "úteis" ou "dispensáveis". Em um contexto como o descrito, o lúdico, o artístico e o poético podem passar despercebidos como lazer, ainda que os estudantes estejam aprendendo sem se dar conta.

\subsection{TERCEIRO CONJUNTO DE ATIVIDADES: AQUALTUNE E AS HISTÓRIAS DA ÁFRICA}

Este conjunto de atividades teve como tema gerador o texto extraído da Revista Ciência Hoje das Crianças denominado Aqualtune e as histórias da África (MASSA, 2014). O texto apresenta a história de Aqualtune, uma princesa africana muito bela e bondosa, e que ao ver sua tribo ser invadida por homens brancos que desejavam faze-los de escravos, lutou bravamente por todos. O texto relata que muitos habitantes da aldeia foram mortos nesta batalha, e outros foram levados como escravos, assim como Aqualtune. Assim, de princesa na África, Aqualtune tornou-se escrava no Brasil.

Ações realizadas:

- A atividade iniciou com a entrega de uma cópia do texto a cada estudante. O primeiro momento destinou-se a uma leitura silenciosa individual e, posteriormente, os estudantes leram em voz alta, mediante a colaboração voluntária de quem desejasse participar.

- Após o primeiro momento, realizou-se um diálogo sobre as diferenças entre o referido texto (lenda) com os livros que eram emprestados na biblioteca (literários), o texto 
anteriormente trabalhado sobre "A maior biblioteca do mundo" (informativo) e os livros utilizados com os professores (didáticos).

- Dando seguimento à atividade, utilizou-se o laboratório de informática da escola onde foram consultados os serviços do Google Maps, Google Street View e Google Earth para mostrar aos estudantes onde se passava a história do texto mencionado, buscar semelhanças e diferenças entre as imagens captadas por estes recursos e o local onde moram, seu ambiente de vivência e o manuseio das ferramentas em si.

- A utilização de enciclopédias eletrônicas deu prosseguimento ao conjunto de atividades. Com uma lista de questões sobre o país do Congo e a cultura africana, os educandos utilizaram a enciclopédia eletrônica Britannica Escola (BRITANNICA, 2016) para responderem às questões propostas. Após, ocorreu um momento de troca de informações e diálogo sobre a experiência.

- Diante do interesse da turma e da variedade de informações reunidas com as atividades anteriores, foi produzido, em cada turma, um cartaz sobre a cultura africana, no qual reuniram-se as informações coletadas juntamente com imagens de temática africana que os estudantes escolheram para ilustrar o cartaz.

Na figura 4, está apresentada a imagem do cartaz elaborado pelos estudantes.

Figura 4 - Cartaz desenvolvido ao final do terceiro conjunto de atividades

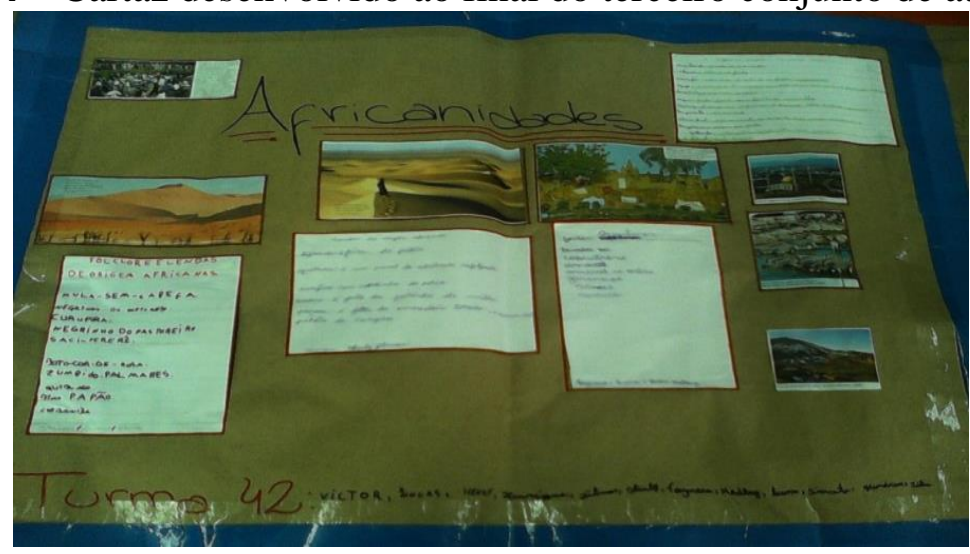

Fonte: Elaboração das autoras

A seguir, apresentamos o Quadro 3, o qual sistematiza as ações pertencentes ao terceiro conjunto de atividades do projeto.

Quadro 3 - Aqualtune e as histórias da África

\begin{tabular}{|c|c|c|c|}
\hline Conteúdos & Competências e Habilidades & Atividades & Avaliação do desenvolvimento \\
\hline \multirow[t]{4}{*}{$\begin{array}{l}\text { Enciclopédias } \\
\text { simples }\end{array}$} & $\begin{array}{l}\text { Compreende as enciclopédias } \\
\text { como fontes mais seguras de } \\
\text { informação. }\end{array}$ & \multirow[t]{4}{*}{$\begin{array}{lr}\text { Utilização da } & \text { Enciclopédia } \\
\text { Eletrônica } & \text { Britannica } \\
\text { Escola. } & \end{array}$} & $\begin{array}{l}\text { Embora a palavra enciclopédia } \\
\text { parecesse desconhecida para a } \\
\text { maioria, compreendiam o } \\
\text { conceito de enciclopédias. }\end{array}$ \\
\hline & $\begin{array}{l}\text { Descreve a organização das } \\
\text { enciclopédias. }\end{array}$ & & \multirow{2}{*}{$\begin{array}{l}\text { Devido ao trabalho anterior } \\
\text { com dicionários, as atividades } \\
\text { envolvendo enciclopédias } \\
\text { foram de fácil assimilação. }\end{array}$} \\
\hline & $\begin{array}{l}\text { Identifica sumários e índices nas } \\
\text { enciclopédias. }\end{array}$ & & \\
\hline & enciclopédias & & $\begin{array}{l}\text { Mostraram-se muito receptivos } \\
\text { e demostraram conhecimento } \\
\text { em buscas deste tipo de fonte. }\end{array}$ \\
\hline Internet & $\begin{array}{l}\text { Faz busca mediante endereços e } \\
\text { buscadores. }\end{array}$ & $\begin{array}{l}\text { Explorando o Google Maps, } \\
\text { Google Street View e } \\
\text { Google Earth. }\end{array}$ & $\begin{array}{lr}\text { Foi grande o entusiasmo com } \\
\text { esta atividade, embora } \\
\text { demonstrassem } \\
\text { conhecimento } & \text { pouco } \\
\text { ferramentas. } & \\
\end{array}$ \\
\hline Biografia & Define biografia. & Análise do texto. & dificuldade \\
\hline
\end{tabular}




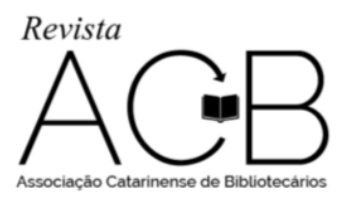

Projeto de Letramento Informacional para estudantes do ensino fundamental: relato de experiência - Cintia Kath Blank e Renata Braz Gonçalves

\begin{tabular}{|c|c|c|c|}
\hline & $\begin{array}{l}\text { Identifica os principais elementos } \\
\text { da biografia. }\end{array}$ & & $\begin{array}{l}\text { diferenciar textos biográficos e } \\
\text { de ficção. }\end{array}$ \\
\hline \multirow[t]{3}{*}{$\begin{array}{l}\text { Planejamento de } \\
\text { estudos em casa }\end{array}$} & Conhece o cronograma de aulas. & $\begin{array}{l}\text { Projeto do letramento } \\
\text { informacional dentro do } \\
\text { quadro de horários. }\end{array}$ & $\begin{array}{l}\text { Rapidamente os discentes } \\
\text { assimilam os dias, horários e } \\
\text { objetivos do projeto. }\end{array}$ \\
\hline & $\begin{array}{l}\text { Utiliza a agenda escolar para } \\
\text { orientar as tarefas de casa. }\end{array}$ & $\begin{array}{l}\text { Levar para o encontro } \\
\text { seguinte } \\
\text { relacionadas a África. }\end{array}$ & $\begin{array}{l}\text { A grande maioria da turma não } \\
\text { levou as ilustrações solicitadas. }\end{array}$ \\
\hline & $\begin{array}{l}\text { Utiliza caderno de estudos para } \\
\text { anotações dos assuntos estudados. }\end{array}$ & $\begin{array}{l}\text { Anotações no decorrer da } \\
\text { atividade. }\end{array}$ & $\begin{array}{lcr}\begin{array}{l}\text { Dificuldade } \\
\text { anotações }\end{array} & \text { para } & \text { fos } \\
\text { assuntor } \\
\text { estudados, bem como retomar } \\
\text { anotações } & \text { de } & \text { encontros } \\
\text { anteriores. } & & \end{array}$ \\
\hline \multirow{2}{*}{$\begin{array}{lr}\text { Orientação } & \text { para a } \\
\text { confecção } & \text { de } \\
\text { cartazes } & \end{array}$} & $\begin{array}{l}\text { Seleciona tipo de materiais - papel, } \\
\text { ilustrações etc. }\end{array}$ & \multirow{2}{*}{$\begin{array}{l}\text { Cartaz sobre a influência de } \\
\text { elementos da cultura } \\
\text { africana em nosso cotidiano. }\end{array}$} & \multirow{2}{*}{$\begin{array}{l}\text { O interesse partiu dos } \\
\text { estudantes, que em sua maioria } \\
\text { já tinham desenvolvido algum } \\
\text { trabalho similar. }\end{array}$} \\
\hline & Elabora cartazes. & & \\
\hline
\end{tabular}

Fonte: Elaboração das autoras

Ao avaliar a realização desse conjunto de atividades, observamos que de todos os temas trabalhados, este foi o que mobilizou mais atenção e participação dos estudantes. Contudo, uma problemática que esteve presente durante o desenvolvimento de todo o projeto foi a dificuldade dos estudantes em tomar nota de pontos importantes dos encontros, anotar lembretes para as próximas aulas e retomar as anotações feitas em encontros anteriores. Este fato dificultou o desenvolvimento do cartaz, que demandava dos educandos a utilização de informações já trabalhadas e a própria atividade de buscar em horário fora do projeto, ilustrações para o cartaz. Passamos ao último conjunto de atividades.

\subsection{QUARTO CONJUNTO DE ATIVIDADES: O LIXO QUE É MEU, É SEU, É DE TODOS NÓS!}

O quarto conjunto de atividades realizadas durante o projeto teve por base o artigo extraído da Revista Ciência Hoje das Crianças denominado "O lixo que é meu, é seu, é de todos nós" (ROCHA, 2014). O artigo aborda questões relacionadas à produção do lixo no contexto atual de produção de bens, a reciclagem e o funcionamento dos lixões. A escolha deste texto deu-se em virtude na constante necessidade da conscientização da importância da reciclagem, da reutilização e, sempre que possível, da redução da quantidade de lixo em nosso cotidiano. A seguir, são expostas as atividades desenvolvidas neste momento do projeto:

- A atividade iniciou com a entrega de uma cópia do texto a cada estudante. O primeiro momento destinou-se a uma leitura silenciosa individual e, posteriormente, a leitura em voz alta, que ocorreu mediante a colaboração voluntária dos discentes que desejassem participar.

- Após, realizou-se um diálogo acerca das diferenças entre o referido texto (informativo) com os livros que eram emprestados na biblioteca (literários), o texto anteriormente trabalhado sobre "Aqualtune e as histórias da África" (lenda) e os livros utilizados com os professores (didáticos).

- Trabalhou-se então com atividades de palavras-cruzadas e caça-palavras com termos representativos do texto utilizado.

No quadro que segue, são relacionadas as atividades desenvolvidas com os conteúdos e habilidades objetivados neste conjunto de atividades: 


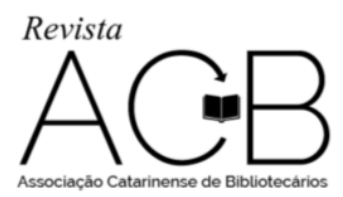

Projeto de Letramento Informacional para estudantes do ensino fundamental: relato de experiência - Cintia Kath Blank e Renata Braz Gonçalves

Quadro 4 - O lixo que é meu, é seu, é de todos nós!

\begin{tabular}{|c|c|c|c|}
\hline Conteúdos & Competências e Habilidades & Atividades & Avaliação do desenvolvimento \\
\hline Palavras-chave & $\begin{array}{l}\text { Identifica as principais palavras } \\
\text { dos textos lidos pelo professor. }\end{array}$ & $\begin{array}{l}\text { Palavras-cruzadas. } \\
\text { Caça-palavras. }\end{array}$ & $\begin{array}{l}\text { Proposta bem recebida pela } \\
\text { turma, mostraram-se desafiados } \\
\text { a solucionar a atividade e } \\
\text { facilidade em indicar as } \\
\text { principais palavras do texto. }\end{array}$ \\
\hline Ficção e não-ficção & $\begin{array}{l}\text { Descreve as diferenças entre os } \\
\text { livros de ficção e não ficção. }\end{array}$ & Análise do texto. & $\begin{array}{l}\text { Facilidade na diferenciação } \\
\text { entre textos informativos e de } \\
\text { ficção. }\end{array}$ \\
\hline \multirow[t]{2}{*}{$\begin{array}{l}\text { Planejamento de } \\
\text { estudos em casa }\end{array}$} & Conhece o cronograma de aulas. & $\begin{array}{l}\text { Projeto do letramento } \\
\text { informacional dentro do } \\
\text { quadro de horários }\end{array}$ & $\begin{array}{l}\text { Rapidamente os discentes } \\
\text { assimilam os dias, horários e } \\
\text { objetivos do projeto. }\end{array}$ \\
\hline & $\begin{array}{l}\text { Utiliza caderno de estudos para } \\
\text { anotações dos assuntos estudados. }\end{array}$ & $\begin{array}{l}\text { Anotações no decorrer da } \\
\text { atividade. }\end{array}$ & $\begin{array}{lcr}\text { Dificuldade } & \text { para } & \text { fazer } \\
\text { anotações } & \text { dos } & \text { assuntos } \\
\text { estudados, bem como } & \text { retomar } \\
\text { anotações } & \text { de } & \text { encontros } \\
\text { anteriores. } & & \end{array}$ \\
\hline
\end{tabular}

Fonte: Elaboração das autoras

Ao avaliar a atividade, constatamos que a mesma foi desenvolvida em tempo menor que o previsto. Cremos que esse fato se deu devido a atividade anterior ter demandado mais tempo que o idealizado, o qual foi motivado pelos próprios discentes. Então, por entender a necessidade de se ouvir e motivar os estudantes optou-se por condensar este último trabalho em prol de atender aos interesses dos grupos de alunos. Destaca-se, contudo, que outros conteúdos e habilidades seriam passíveis de serem trabalhados com esta atividade, como, por exemplo, a utilização de dicionários e enciclopédias para aprofundar termos relativos à temática reciclagem, a elaboração de esquemas e resumos sobre o artigo, localização de materiais referentes à reciclagem nas coleções da biblioteca da escola e a utilização de dicionários bilíngues conforme sugere Gasque (2012).

\section{CONSIDERAÇÕES FINAIS}

À guisa de conclusão deste relato e avaliação geral do projeto de letramento informacional, entendemos que este trabalho constitui-se em contribuição significativa para a área de letramento informacional em bibliotecas escolares, uma vez que apresenta a avaliação da aplicação de uma metodologia de trabalho proposta para ser desenvolvida nesse universo, caracterizado pela escassez de materiais que proporcionem uma orientação prática-metodológica para o desenvolvimento do letramento informacional nas escolas públicas do nosso país.

A simplicidade para elaboração das atividades, bem como o uso do material já existente nas bibliotecas foram adotados de forma proposital, a fim de demonstrar que é possível desenvolver esse tipo de trabalho ainda que os recursos sejam parcos. A explicitação detalhada do processo, bem como a avaliação de cada atividade permite que outros profissionais (bibliotecários e/ou professores) que leiam esse artigo e possam utilizá-lo como referência para criação de novas atividades. Lembramos que é necessário propor um conjunto de atividades adequado às necessidades específicas de cada público.

Durante a avaliação das atividades, foi possível identificar pontos positivos e negativos no desenvolvimento do projeto de letramento informacional, dos quais destacamos, nessa conclusão, os mais relevantes. Como pontos positivos, consideramos a receptividade dos discentes, que se mostravam dispostos a participar das tarefas e demostravam conhecimentos prévios de vários pontos trabalhados. Além de mudanças de atitudes no que se refere ao uso de obras de referência, percebeu-se a ampliação do repertório cultural, sistematização das leituras, desenvolvimento da oralidade, interpretação e aproximação com diferentes gêneros literários. Deve-se este fato ao se utilizar de textos e atividades já familiares a eles, mas que ainda assim mostravam algum ineditismo, seja pelos recursos utilizados, seja pela dinâmica trabalhada. 
Já como pontos negativos, identificamos a dificuldade dos estudantes em organizar seus materiais de estudo como, por exemplo, os apontamentos realizados durante as atividades. Esse fato dificultou o desenvolvimento de algumas atividades tornando-se um empecilho para o trabalho com tarefas mais complexas como a pesquisa escolar.

Percebeu-se a falta de autonomia ao sistematizar de forma escrita conhecimentos diferentes daqueles trabalhados com seus respectivos professores. Creditamos este fato a um método de ensino e de aprendizagem amplamente presente nas escolas: a cópia. Ao serem convidados a desenvolver uma atividade mais livre de construção de conhecimentos, ao contrário das tradicionais aulas copiadas, os estudantes demonstraram insegurança e falta de iniciativa para realização desse tipo de atividade, fato que pode estar relacionado à falta de familiaridade com esse tipo de ação.

Essa constatação vai ao encontro do que já identificaram Gasque e Tescarolo (2010, p. 46) quando afirmavam que "Apesar da discussão sobre a importância do sujeito ativo na aprendizagem, do espírito investigativo, do desenvolvimento da autonomia, do senso crítico e ético propiciadas pelas pesquisas, ainda assim, estudos [...] evidenciam problemas com as práticas de investigação na educação básica".

Outro fator negativo observado foi a pouca colaboração por parte dos professores responsáveis pelas turmas e outros setores da escola com as atividades propostas pela biblioteca. Percebeu-se neste ponto, uma falta de cultura escolar voltada para a informação e o conhecimento, desconsiderando a relevância da colaboração entre todos. Infelizmente, este fato compromete o pleno desenvolvimento da proposta do letramento informacional, uma vez que a colaboração é fundamental para o êxito de projetos deste tipo (CAMPELLO, 2009; GASQUE, 2012).

Por fim, consideramos muito positiva a vivência ora relatada. Os pontos positivos observados mostram-se como guia para a continuidade do projeto, assim como os pontos negativos uma motivação para a sua melhoria. Pontua-se assim, a importância do desenvolvimento de projetos ligados à pesquisa, informação e conhecimento no ambiente escolar, bem como do compartilhamento dos saberes gerados nestas experiências, assim como a necessidade da continuidade de projetos com este viés, de maneira a trabalhar diferentes dinâmicas com os estudantes para que atinjam a autonomia no seu processo de aprendizagem.

\section{REFERÊNCIAS}

BELLUZZO, R. C. L. B. O conhecimento, as redes e a competência em informaçÃo (coinfo) na sociedade contemporânea: uma proposta de articulaçÃo conceitual. Perspectivas em Gestão \& Conhecimento, v. 4, n. Esp., 2014. Disponível em: http://basessibi.c3sl.ufpr.br/brapci/v/a/16057. Acesso em: 31 Jan. 2017.

Construção de mapas: desenvolvendo competências em informação e comunicação. 2. ed. Bauru: Cá Entre Nós, 2007.

BRITANNICA Escola. Disponível em: http://escola.britannica.com.br. Acesso em: 11 abr. 2016.

CAMPELLO, Bernadete Santos. Letramento informacional: função educativa do bibliotecário na escola. Belo Horizonte: Autêntica, 2009.

CAREGNATO, Sônia. O desenvolvimento de habilidades informacionais: o papel das bibliotecas universitárias no contexto da informação digital em rede. Revista de Biblioteconomia e Comunicação, Porto Alegre, v. 8, p. 47-55, 2000. 


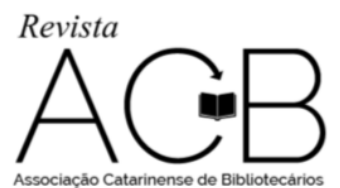

Projeto de Letramento Informacional para estudantes do ensino fundamental: relato de experiência - Cintia Kath Blank e Renata Braz Gonçalves

DICIONÁRIO Priberam da Língua Portuguesa. [20--]. Disponível em: https://www.priberam.pt/DLPO/. Acesso em: 11 abr. 2016.

DUDZIAK, Elizabeth Adriana. Os faróis da sociedade de informação: uma análise crítica sobre a situação da competência em informação no Brasil. Informação \& Sociedade: estudos, João Pessoa, v.18, n. 2, p. 41-53 2008.

FUNARI, Raquel dos Santos. A maior biblioteca do mundo. Ciência Hoje das Crianças, Rio de Janeiro, v. 25, n. 234, p. 2-5, 2012.

FUNDA NACIONAL DE DESENVOLVIMENTO DA EDUCAÇÃO. Apresentação. 2012. Disponível em: http://www.fnde.gov.br/programas/biblioteca-da-escola/biblioteca-da-escola-apresentacao. Acesso em: 10 abr. 2016.

GASQUE, Kelley Cristine Dias. Letramento Informacional: pesquisa, reflexão e aprendizagem. [e-book]. Brasília: UNB, 2012.

Arcabouço conceitual do letramento informacional. Ciência da Informação, v.39, n.3, p. 83-92, set./dez. 2010.

GASQUE, Kelley Cristine Dias; TESCAROLO, Ricardo. Desafios para implementar o letramento informacional na educação básica. Educ. rev., Belo Horizonte, v. 26, n. 1, p. 41-56, Apr. 2010. Disponível em: http://www.scielo.br/scielo.php?script=sci_arttext\&pid=S010246982010000100003\&lng=en\&nrm=iso. Acesso em: 06 jan. 2017.

JOGO da vida do livro. Revista Nova Escola, Rio de Janeiro, v. 263, jun./jul., 2013.

MASSA, Ana Cristina. Aqualtune e as histórias da África. Ciência Hoje das Crianças, Rio de Janeiro, v. 27, n. 262, p. 10-11, 2014.

PIAGET, Jean. A formação do símbolo na criança, imitação, jogo, sonho, imagem e representação de jogo. São Paulo: Zanhar, 1964.

ROCHA, Marcelo. O lixo que é meu, é seu, é de todos nós. Ciência Hoje das Crianças, Rio de Janeiro, v. 27, n. 261, p. 6-9, 2014.

SOARES, Magda; MACIEL, Francisca (org.). Alfabetização. Brasília: MEC/INEP/COMPED, 1998. Série Estado do Conhecimento.

UNIVERSIDADE ESTADUAL PAULISTA. Carta de Marília. In: Seminário de Competência em Informação, 3., 2014, Marília. Anais eletrônicos... Marília: UNESP, 2014. Disponível em: http://www.lti.pro.br/userfiles/downloads/CARTA_de_Marilia.pdf. Acesso em: 02 maio 2016.

ZURKOWSKI, Paul G. Information services environment relationships and priorities. Washington D.C.: National Commission on Libraries, 1974. Disponível em: http://files.eric.ed.gov/fulltext/ED100391.pdf. Acesso: 22 nov. 2014. 


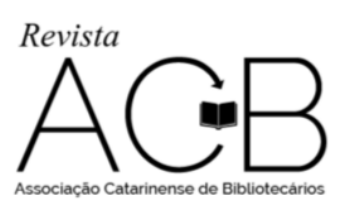

Projeto de Letramento Informacional para estudantes do ensino fundamental: relato de experiência - Cintia Kath Blank e Renata Braz Gonçalves

\title{
LITERACY PROJECT FOR INFORMATIONAL EDUCATION STUDENTS BASICS: EXPERIENCE REPORT
}

\begin{abstract}
This text aims to present the implementation and evaluation of an information literacy project that was developed during the year 2015 by the librarian of a public elementary school in Rio Grande city - Brazil. Initially, it presents a brief theoretical reference about informational literacy, later describes the project, its objectives, stages and finally analyzes the results achieved with the implementation of the project. Subsidized theoretically and methodologically by the production of Gasque (2012) systematized in the book "Information Literacy", and using resources provided by the Ministry of Education for school libraries, this project aimed to promote the development of skills and informational skills in students of the 4th year of the Elementary school. This experience report seeks to disseminate the experiences and evaluations of this project, such as the importance and feasibility of the project, the motivation of students for the development of activities, the nonexistence of a culture of information and research in the school community, and the requirement adaptation of the materials to the objectives of information literacy. The final considerations Highlight the importance of the development and communication by the librarians of practical activities involving information literacy, as well as the production of specific didactic and theoretical guidelines for the application of informational literacy in the Brazilian educational, social and cultural contexts.
\end{abstract}

Keywords: Information Literacy. School Library. Behavior Information.

RECEBIDO EM: 16-08-2016

ACEITO EM: 07-02-2017 